\title{
İçsel Boş Zaman Motivasyon Ölçeği Geçerlilik ve Güvenirlik Çalışması
}

\author{
DOI: $10.26466 /$ opus.705201
}

*

\author{
Ali Selman Özdemir* - Tebessüm Ayyıldız Durhan** - Suat Karaküçük*** \\ * Dr, Öğr, Üyesi, Uluslararası Kıbrıs Üniversitesi, Beden Eğitim ve Spor Y.O \\ E-Posta: ozdemiraliselman@gmail.com ORCID: 0000-0003-1736-7602 \\ ** Dr, Gazi Üniversitesi, Rekreasyon Bölümü \\ E-Posta: tebessum@gazi.edu.tr \\ ORCID: 0000-0003-2747-6933 \\ *** Prof. Dr., Gazi Üniversitesi, Rekreasyon Bölümü \\ E-Posta: ksuat@gazi.edu.tr \\ ORCID: $\underline{0000-0001-9144-7307}$
}

\section{Öz}

Bu çalısmanın amacı içsel boş zaman motivasyon ölçeğinin geçerlik ve güvenirlik analizlerini yaparak literatüre kazandırmaktır. Araştırma test tekrar test yöntemiyle toplam 748 öğrenciden toplanan veriler ışığında yapılan analizlere dayanmaktadır. Veriler 353 katılımo ile KMO-Barlett testine tabi tutulmuş ve örneklem büyüklüğ̈̈̈n̈̈n analizi yapmak adına uygun olduğu $(.92 ; 3366,957, p<0,001)$ belirlendikten sonra açımlayıc faktör analizinden yararlanılmıştır. Açımlayıc faktör analizi ile geçerli bir yapı oluşturulmaya çalısılmış, 5 alt boyut ve 23 maddeden oluşan nihai ölçek formuna ulaşılmıştır. Yapılan açımlayıcı faktör analizi sonucu kesme değeri 40 olarak alınmış, açıklanan varyans değerinin toplamda \%57,53 olduğu döndürülmüş bileşenler analizinde 5 alt boyut altında toplandığı saptanmıştır. Ölçek maddelerinden birbirine yük verdiği tespit edilen 7. madde testten çıkartılmıştır, ayrıca 5. Alt boyut maddeleri ters kodlanmaktadır. Test tekrar test yöntemiyle 395 katılımcı üzerinde yapılan ikinci veri toplama işleminden sonra yap doğrulayıc faktör analizi ile sınanmıştır. Doğrulayıcı faktör analizinin yapı geçerliliğine kanıt oluşturduğu görülmektedir (RMSEA .070, NFI 0.96, CFI 0.96, NNFI 0.96, $x^{2} / d f$ 2.94). Sonuç olarak katulimcularm içsel boş zaman motivasyonunun belirlenmesine yönelik geliştirilen ölçüm aracı, boş zamanlara yönelik içsel motivasyonu ölçmede geçerli ve güvenilir bir araç olarak ortaya koyulmuştur.

Anahtar Kelimeler: İçsel, boş zaman, motivasyon 


\title{
Validity And Reliability Analysis of Intrinsic Leisure Motivation Scale
}

\begin{abstract}
The aim of this study is to make the validity and reliability analyzes of the intrinsic leisure motivation scale and gain them to the literature. The research is based on the analysis conducted in the light of data collected from 748 students by test-retest method. The data were subjected to KMO-Barlett test with 353 participants and exploratory factor analysis was used after determining that sample size was suitable for analysis $(.92 ; 3366,957, p<0.001)$. A valid structure was tried to be established by exploratory factor analysis and a final scale form consisting of 5 sub-dimensions and 23 items was reached. As a result of exploratory factor analysis, the cut-off value was taken as .40, and the variance value was $57.53 \%$ in total. Item 7 , which was found to give a load to each other from the scale items, was excluded from the test, and 5. Subdimension items were reverse coded. The test was tested by structure confirmatory factor analysis after the second data collection on 395 participants by retest method. Confirmatory factor analysis appears to provide evidence of construct validity (RMSEA .070, NFI 0.96, CFI 0.96, NNFI 0.96, $x 2$ / df 2.94). As a result, the measurement tool developed to determine the participants' intrinsic leisure motivation has been put forward as a valid and reliable tool in measuring internal motivation for leisure.
\end{abstract}

Keywords: Intrinsic, leisure, motivation 


\section{Giriş}

Boş zaman motivasyonu araştırmaları, boş zaman aktivitelerine katılımın altında yatan psikolojik ve sosyolojik nedenleri ele almakla birlikte (Chen ve Pang, 2012), insanların boş zaman değerlendirme biçimlerini, davranışlarının sebeplerini ve katılımlarının sonuçlarını aydınlatması yönüyle, boş zaman araştırmalarının merkezinde yer almaktadır (Manfredo ve diğ., 1996). Motivasyon, insan davranışını başlatan, yönlendiren ve sürdüren güçleri ifade eder (Iso-Ahola, 1999). Davranış bilimlerinde motivasyon, içten gelen itici kuvvetlerle belirli bir hedefe doğru yönelen amaçlı davranışlar olarak tanımlanırken; istekleri, arzuları, ihtiyaçları, dürtüleri (açlık, susuzluk vb. gibi) ve ilgileri içermektedir (Coleman ve diğ., 2000). Davranışın nedenini, öncüllerini ve sonuçlarını ele alan Öz-Belirleme Kuramı ise (Deci ve Ryan, 2000), boş zaman, egzersiz ve spor motivasyonunda en etkili teori olarak karşımıza çımaktadır (Clancy ve diğ., 2016).

Öz-Belirleme Kuramı (Deci ve Ryan, 1985), bir davranışa yol açan, farklı nedenlere veya hedeflere dayanan motivasyonları birbirinden ayırmaktadır. Buna göre ilk çalışmalar, içsel ve dişsal olmak üzere iki tür motivasyon olduğunu varsaymıştır. İcsel motivasyon; bireyin içsel tatminini saglamak için yaptığ faaliyetlerdir. Baskılar veya öduiller için değll, eglence, görev bilinci, beceri geliștirme gibi duyguları tatmin etmek için harekete geçmektedir (White, 1959). İçsel motivasyon, sadece onu gerçekleştirmekten elde edilen zevk ve memnuniyet için bir aktiviteye katılmak anlamına gelir (Deci, 1975). Bir faaliyetin, özel bir sonuçtan ziyade doğal bir memnuniyet için yapılması olarak tanımlanır. Dıss,sal motivasyon ise; bireyin dışındaki etmenlerdir ve içsel motivasyonun tam tersidir. Genellikle, bireyin içsel motivasyonlar yoluyla elde edemeyeceği sonuçlara ulaşmak için kullanılır. Yaygın dışsal motivasyonlar, istenen davranışı görmek üzere ödüller (para kazanma, dersten geçme vb. gibi) ve istenmeyen davranış karşısındaki cezalardır (trafik cezası, diskalifiye olma vb. gibi) (Ryan ve Deci, 2000b). Birey, içsel olarak motive edildiğinde, dış etmenler, baskılar veya ödüller yerine eğlenmek veya aktivite ile uğraşmak için harekete geçer. İçsel motivasyon, karşılaştıkları yeni nesneleri sürekli olarak kavramaya, atmaya, 1sırmaya, ezmeye veya ses çıkarmaya çalışan bebeklerde açıkça görülebilir. Yetişkinler ise genellikle bulmaca çözerken, resim yaparken, bahçe ile uğraşırken, kitap okurken veya film izlerken kendiliğinden motive olmaktadırlar. Kısaca bireyin, sevmediği bir 
derse zorunlu olarak çalışmasını sağlayan not kaygısı ya da dersten kalma korkusu dışsal motivasyon, sevdiği ve ilgi duyduğu bir derse ise hiçbir zorlama veya not kaygısı olmadan ekstra çalışması veya sınıf adına sorumluluk alması ise içsel motivasyonlarla ilgilidir.

İçsel motivasyon, doğal bir motivasyon eğilimidir ve bilişsel, sosyal ve fiziksel gelişimde kritik bir unsurdur (Ryan ve Deci, 2000a). Weissinger ve Bandalos (1995), içsel boş zaman motivasyon eğilimini oluşturan dört bileşenin kavramsal tanımlarını aşağıdaki gibi yapmıştır:

Öz-Belirleme (Özerklik): Bu bileşen, içsel ihtiyaçların farkındalığı ve bu ihtiyaçlara dayalı özgür seçimler yapma arzusu ile karakterizedir. Bu içsel motivasyon bileşeni yüksek olan kişiler, boş zaman davranışlarının kontrolünü hissetme ve yüksek derecede isteklilik sergileme eğilimindedir.

Yeterlik: Yeterlik; beceri, yetenek ve etkililik (verimlilik) hakkında geri bildirim sağlaması ile karakterizedir. Bu içsel motivasyon bileşeni yüksek olan kişiler, yetkinlik üzerine geribildirim alabildikleri boş zaman davranışları sergileme eğilimindedir.

Bağlılık: Bağllık, boş zaman davranışlarından kopmak yerine derin bir katılım eğilimi ile karakterizedir. Bu içsel motivasyon bileşeni yüksek olan kişiler, boş zaman davranışlarına değer verme ve yaşamlarında boş zamanlarına adanmış hissetme eğilimindedir.

Mücadele (Zorluk): Mücadele, kendi sınırlarının zorlanması ve kendine has uyaranlarla deneyim aranması eğilimi ile karakterizedir. Bu içsel motivasyon bileşeni yüksek olan kişiler, becerilerinin biraz üzerinde olan boş zaman davranışlarını seçme eğilimindedir. Bu durum, caydırıcı veya tehdit edici değil, zorlayıcı olarak algılanmaktadır.

İçsel motivasyon teorisi, uluslararası literatürde; terapötik rekreasyon, çocuk oyunları, fiziksel sağlık, akış (flow), serbest zaman hizmetlerinin değerlendirilmesi, boş zaman aktivitesine katılımdan vazgeçme, rekreasyonel alışveriş ve rekreasyonel turizm gibi çeşitli boş zaman davranış alanları üzerinde uygulanmıştır (Levy, 1971; Csikszentmihalyi, 1975b; Weissinger ve IsoAhola, 1984; Iso-Ahola, 1982; Mannell, Zuzanek ve Larson, 1988; Backman ve 
Crompton, 1990; Lesser ve Forsythe, 1989; Iso-Ahola, 1983). Alanyazın incelendiğinde, boş zaman motivasyonları üzerine ülkemizde sınırlı sayıda ölçek geliştirme ve uyarlama çalışması olduğu görülmektedir (Gürbüz, 2006; Güngörmüş, 2012; Özdemir ve diğ., 2016).

Bu çalışmanın amacl; bireylerin boş zaman tercih ve davranışlarının aydınlatılmasında, boş zaman hizmet ve programlarının ihtiyaçlara uygun şekilde yeniden tasarlanmasında, gelişim ve eğitim psikolojisinde boş zaman davranışlarını aydınlatma boyutunda önemli katkı sağlayacağı düşünülen, Deci, Ryan (1985a), Kobasa (1979) ve arkadaşlarının çalışmalarına dayanarak Weissinger ve Bandalos'un (1995) geliştirdiği ve orijinal ad ^ "Instrinsic Motivation Scale" (İçsel Boş Zaman Motivasyonları Ölçeği) olan ölçeğin Türkçe uyarlamasını yaparak geçerlik ve güvenirliğini test etmektir.

\section{Yöntem}

Deci, Ryan (1985a), Kobasa (1979) ve arkadaşlarının araştırmalarına dayanarak Weissinger ve Bandalos'un (1995); Boş zaman davranışlarında içsel motivasyon eğilimindeki bireysel farklılıkları ölçmek amacıyla geliştirdiği ve orijinal ad1 "Instrinsic Motivation Scale (ILM)" (İçsel Boş Zaman Motivasyonları Ölçeği) olan ölçeğin Türkçe uyarlamasını yaparak geçerlik ve güvenirliğini test etmeyi amaçlayan araştırmada, ölçeğin orijinal versiyonu 24 madde ve dört alt boyuttan oluşmaktadır. Altışar maddeden oluşan dört alt boyut için Cronbach's Alpha güvenirlik katsayıları sırasıyla; Öz-Belirleme (Özerklik) .637; Yeterlik .689; Bağlllık .727; ve Mücadele (Zorluk) .724'dür. 24 maddeli ölçeğin toplam Cronbach's Alpha güvenirlik katsayısı ise .856'dır. İçsel Boş Zaman Motivasyonu (ILM) Ölçeği'nin 24 maddelik orijinal versiyonu, tatmin edici bir güvenilirlik göstermiştir ve düşük madde sayısı ile çoğu araştırma ortamında kullanım için pratiktir (Weissinger ve Bandalos, 1995). Ölçek cevap seçeneklerinde, 1=Kesinlikle Katılmıyorum ile 7=Kesinlikle Katılıyorum şeklinde yedi puanlık bir yanıt aralığı sunan derecelendirme kullanılmış, " 7 " en yüksek içsel motivasyon puanını temsil etmiştir. Negatif olarak ifade edilen üç madde için $(6,13,18)$ ters kodlama yapılarak puanlama yapılmışıı.

Araştırmada veriler Gazi Üniversitesi ve Bülent Ecevit Üniversitesi öğrencilerinden kolayda örnekleme yöntemi ile elde edilmiş, test tekrar test yöntemiyle veriler analiz edilmiştir. Öncelikle veriler 353 katılımcıdan elde 
edilmiş ve KMO-Barlett testine tabi tutularak örneklem büyüklüğünün analizi yapmak adına uygun olup olmadığı belirlenmiştir. Daha sonar açımlayıcı faktör analizinden yararlanılmış, 6,13 ve 18. maddeler ters kodlandıktan sonra açımlayıcı faktör analizi ile geçerli bir yapı oluşturulmaya çalışılmış, oluşturulan yapıya dair iç güvenirlik katsayılarının yapıyı destekler düzeyde olduğu belirlenmiştir. saptanmıştır. Aynı grup üzerinde yapılan ikinci veri toplama aşamasının ardından 395 katılımcı araştırmaya dahil olmuş, elde edilen veriler ışığında yapı, doğrulayıc faktör analizi ile sınanmıştır. Elde edilen ölçüm aracının içsel boş zaman motivasyonunu ölçmede geçerli ve güvenilir bir yapıda olduğu analizler sonucu belirlenmiştir. Elde edilen bulgulara aşağıda yer verilmektedir.

\section{Bulgular}

Tablo 1. İçsel boş zaman motivasyonu ölçeği KMO ve Barlett Testi sonuçlam

\begin{tabular}{lll}
\hline KMO ve Bartlett's Testi & & \\
\hline Kaiser-Meyer-Olkin Örneklem Uyum Ölçüsü & & 0,927 \\
\hline Barlett Küresellik Testi & $\mathrm{x}^{2}$ & 3366,957 \\
\cline { 2 - 3 } & $\mathrm{sd}$ & 276 \\
\cline { 2 - 3 } & $\mathrm{p}$ & 0,000 \\
\hline
\end{tabular}

Kaiser Meyer Olkin Örneklem Grubunun yeterliliğine yönelik test sonuçları ile Barlett Küresellik testi sonuçları örneklem grubunun yapılacak analizler için yeterli olduğunu gösterir düzeydedir $(.92 ; 3366,957, \mathrm{p}<0,001)$. 
Tablo 2. İçsel boş zaman motivasyon ölçeği açımlayıcı faktör analizi sonuçları

\begin{tabular}{|c|c|c|c|c|c|c|c|c|}
\hline & $\begin{array}{l}\frac{\pi}{\pi} \\
\frac{\pi}{2}\end{array}$ & 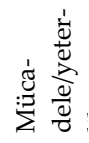 & 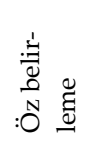 & 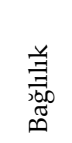 & 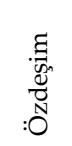 & 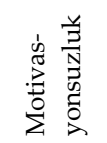 & 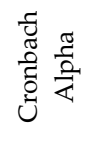 & 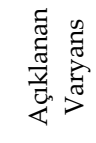 \\
\hline Boş zamanlarımda mücadeleyi seviyorum. & 10 & .760 & & & & & & $\% 35.50$ \\
\hline $\begin{array}{l}\text { Boş zaman aktivitelerim becerilerimi } \\
\text { zorladığında kendimi iyi hissederim. }\end{array}$ & 15 & .683 & & & & & .85 & \\
\hline $\begin{array}{l}\text { Boş zaman aktivitelerine katılmam beni yetkin } \\
\text { hissettiriyor. }\end{array}$ & 16 & .606 & & & & & & \\
\hline Boş zamanlarımda bilinmeyeni denemeye hazırım. & 14 & .578 & & & & & & \\
\hline $\begin{array}{l}\text { Boş zaman uğraşlarımda etkin olmak için } \\
\text { çabalıyorum. }\end{array}$ & 4 & .570 & & & & & & \\
\hline $\begin{array}{l}\text { Arkadaşlarım boş zaman aktivitelerinde } \\
\text { yetenekli olduğumu düşünürler. }\end{array}$ & 9 & .565 & & & & & & \\
\hline $\begin{array}{l}\text { Yeteneklerimin biraz ötesinde olan boş zaman } \\
\text { aktivitelerinden hoşlanırım. }\end{array}$ & 5 & .500 & & & & & & \\
\hline Boş zaman aktivitelerim tüm dikkatimi çekiyor. & 8 & .418 & & & & & & \\
\hline $\begin{array}{l}\text { Boş zamanlarımı nasıl kullanacağıma karar } \\
\text { verirken kişisel ihtiyaçlarımı dinlerim. }\end{array}$ & 24 & & .680 & & & & .85 & $\% 6.62$ \\
\hline $\begin{array}{l}\text { Boş zamanlarımı neyin tatmin edeceğini biliyor } \\
\text { gibiyim. }\end{array}$ & 21 & & .690 & & & & & \\
\hline $\begin{array}{l}\text { Boş zamanlarımda yaptığım şeyler, } \\
\text { yeteneklerim hakkında kendimi iyi hissettirir. }\end{array}$ & 22 & & .679 & & & & & \\
\hline $\begin{array}{l}\text { Boş zaman aktivitelerim kendimi etkili bir } \\
\text { insan gibi hissettirir. }\end{array}$ & 23 & & .670 & & & & & \\
\hline $\begin{array}{l}\text { Boş zamanlarımda en çok hoşlandığım şey } \\
\text { özgür seçimler yapabilmemdir. }\end{array}$ & 17 & & .601 & & & & & \\
\hline $\begin{array}{l}\text { Boş zaman aktivitelerimden ödün vermek } \\
\text { istemiyorum. }\end{array}$ & 19 & & .575 & & & & & \\
\hline $\begin{array}{l}\text { Boş zamanlarımda hayatımın kontrolüm } \\
\text { altında olduğunu hissediyorum. }\end{array}$ & 1 & & & .761 & & & .75 & $\% 5.72$ \\
\hline $\begin{array}{l}\text { Boş zamanlara hayatımın diğer alanlarına } \\
\text { olduğu kadar adanırım. }\end{array}$ & 2 & & & .714 & & & & \\
\hline $\begin{array}{l}\text { Boş zaman aktivitelerimden ne istediğimi bili- } \\
\text { yorum. }\end{array}$ & 3 & & & .696 & & & & \\
\hline $\begin{array}{l}\text { Boş zaman aktivitelerim hayatımın merkezini } \\
\text { oluşturur. }\end{array}$ & 11 & & & & .765 & & .71 & $\% 5.28$ \\
\hline Boş zaman, en iyi olduğum şeydir. & 20 & & & & .702 & & & \\
\hline Boş zaman, hayatımda önemlidir. & 12 & & & & .414 & & & \\
\hline $\begin{array}{l}\text { Boş zamanlarımda istediğimi yapamayacağımı } \\
\text { hissediyorum }\end{array}$ & 6 & & & & & .752 & .70 & \%4.39 \\
\hline $\begin{array}{l}\text { Boş zaman tamam/iyi ama hayatımdaki diğer } \\
\text { şeyler daha önemli }\end{array}$ & 13 & & & & & .719 & & \\
\hline $\begin{array}{l}\text { Becerilerimi zorluyorsa boş zamandan zevk } \\
\text { almam. }\end{array}$ & 18 & & & & & .613 & & \\
\hline
\end{tabular}


Yapılan açımlayıcı faktör analizi sonucu kesme değeri 40 olarak belirlenmiş, döndürülmüş bileşenler analizinde beş faktörlü yapı sergileyen ölçeğin, birbirine yük veren madde bulunması kuralına yönelik olarak madde 1 ölçekten çıkartılarak yapı sınanmıştır.

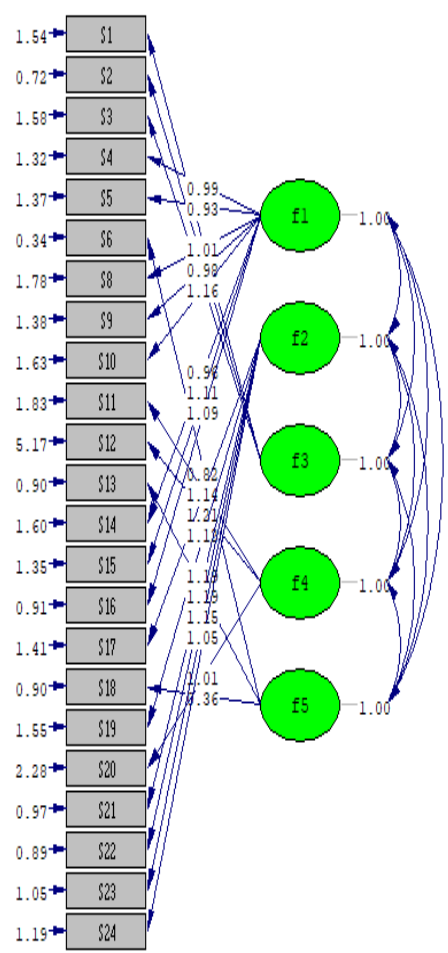

Chi-Square $=647.12, \mathrm{df}=220, \mathrm{p}-\mathrm{value}=0.00000, \mathrm{RMSEA}=0.070$

Şekil 1. Doğrulayıcı faktör analizi diyagramı

\section{Doğrulayıcı Faktör Analizine Dair Bulgular}

Yapılan açımlayıcı faktör analizi sonrası elde edilen yapının geçerliliğini ve doğruluğunu test etmek üzere doğrulayıcı faktör analizi yapılmıştır. Test tekrar test sonrası yapılan DFA'nın yapı geçerliliğine kanıt oluşturduğu görülmektedir (RMSEA .070, NFI 0.96, CFI 0.96, NNFI 0.96, x²/df 2.94). 
Tablo 3. Uyum ölçüleri ve model uyumu için sınır değerleri (Özdamar, 2016, s.185; Özdamar, 2013, s.242).

\begin{tabular}{lllll}
\hline Uyum Ölçüsü & $\begin{array}{l}\text { İdeal } \\
\text { Uygunluk Değerleri }\end{array}$ & $\begin{array}{l}\text { Kabul } \\
\text { Edilir Uyum }\end{array}$ & Uyumsuzluk & $\begin{array}{l}\text { Elde } \\
\text { edilen değerler }\end{array}$ \\
\hline RMSEA & $0-0.05$ & $0.05-0.09$ & $>0.10$ & 0.70 \\
\hline CFI & 1 & $0.90-0.99$ & $<0.90$ & 0.96 \\
\hline NNFI & 1 & $0.95-0.99$ & $<0.95$ & 0.96 \\
\hline $\mathrm{x}^{2} / \mathrm{df}$ & $<=2$ & $2-5$ & $5+$ & 2.94 \\
\hline
\end{tabular}

\section{Tartışma ve Sonuç}

İçsel boş zaman motivasyonu; belirlenen hedeflere ulaşmada harcanan zaman, efor ve süreçten alınan keyif temelli önemli bir unsurdur. Örneğin bir dağc zirveye ulaşmak için tırmanış yapmaktan ziyade tırmanmak için zirveye ulaşır ve içsel boş zaman motivasyonu doğrultusunda boş zaman etkinliklerini gerçekleştirir (Csikszentmihalyi, 1990). Bu bağlamda öz-belirleme yeterlik, bağlılık, mücadele gibi pek çok faktörün bir çatı altında toplandığı boş zaman aktivitelerine katılımın altında yatan psikolojik ve sosyolojik nedenlerin belirlendiği içsel boş zaman motivasyonu bireylerin boş zaman katılımındaki etken güdülerini belirlemede önemli bir araç olacaktır. Bu noktadan hareketle, bu çalışmanın amacı içsel boş zaman motivasyon ölçeğinin geçerlik ve güvenirlik analizlerini yaparak literatüre kazandırmaktır.

Araştırma test tekrar test yöntemiyle toplam 748 öğrenciden toplanan veriler ışığında yapılan analizlere dayanmaktadır. Veriler 353 katılımcı ile KMOBarlett testine tabi tutulmuş ve örneklem büyüklügünün analizi yapmak adına uygun olduğu $(.92 ; 3366,957, \mathrm{p}<0,001)$ belirlendikten sonra açımlayıcı faktör analizinden yararlanılmıştır. Açımlayıcı faktör analizi ile geçerli bir yapı oluşturulmaya çalışılmış, 5 alt boyut ve 23 maddeden oluşan nihai ölçek formuna ulaşılmıştır. Yapılan açımlayıcı faktör analizi sonucu kesme değeri .40 olarak alınmış, açıklanan varyans değerinin toplamda $\% 57,53$ olduğu döndürülmüş bileşenler analizinde 5 alt boyut altında toplandığı saptanmıştır. Ölçek maddelerinden birbirine yük verdiği tespit edilen 7 . madde testten çıkartılmıştır. Ayrıca 5. Alt boyut maddeleri ters kodlanmaktadır. Test tekrar test yöntemiyle 395 katılımc üzerinde yapılan ikinci veri toplama işleminden sonra yapı doğrulayıc faktör analizi ile sınanmıştır. Doğrulayıcı faktör analizinin yapı geçerliliğine kanıt oluşturduğu görülmektedir (RMSEA .070, NFI 0.96, CFI 0.96, NNFI 0.96, x²/df 2.94). 
İçsel boş zaman motivasyonunun belirlenmesine yönelik Weissinger ve Bandalos'un (1995) geliştirdiği ölçüm aracı 9 ayrı çalışmadan esinlenerek hazırlanmıştır. Öz belirleme, yetkinlik, bağlılık ve mücadele alt boyutları olmak üzere 4 alt boyut ve 24 maddeden oluşmaktadır. Araştırma kapsamında elde edilen 5 alt boyuttan farklı olarak 4 alt boyutta açıklanan yapı .87 ila .91 arasında değişen iç tutarlılık katsayılarına sahip güvenilir bir ölçüm aracı olarak ortaya koyulmuştur. Boş zaman motivasyonuna yönelik araştırmaların boş zaman faaliyetlerine katılmak için psikolojik ve sosyolojik nedenlerin belirlenmesi olarak tanımlanması mümkündür (Chen ve Pang, 2012). İçsel boş zaman motivasyonunda ve boş zaman motivasyonda kaçış, ilişkileri geliştirmek, kişisel ustalık, kazanma, ilgi veya eğlence, algılanan yetkinlik, çabaönem gibi unsurlar önem teşkil etmektedir (Dillard ve Bates, 2011; Tsigilis ve Theodosiou, 2003). Bu parametrelerin belirlenmesine yönelik araştırmalardan biri olan boş zaman motivasyonunu incelemek ve değerlendirmek için bir araç geliştirmeki hedefleyen araştırma bulguları; boş zaman aktivitelerine katılımın psikolojik ve sosyolojik nedenlerini değerlendirmekte ve dört alt boyutta incelenmektedir. Entelektüel, sosyal, yetkinlik-ustalık ve uyarıcılıktan kaçınma olarak adlandırılan ölçüm aracında veriler nihai form ile 1205 kişiye uygulanarak 90 oranında yüksek bir iç tutarlılık katsayısı elde etmiştir. Boş zaman motivasyonu ölçümleri içsel boş zaman motivasyonun belirlenmesine etkin araçlar olarak değerlendirilmektedir. Bir diğer araştırmada Beard ve Ragheb'in geliştirdiği boş zaman motivasyonu ölçeğinin tatilden önce ifade edilen ihtiyaçları ölçmek adına uyarlanan versiyonunda yine benzer alt boyutlar elde edilmiştir (Lounsbury ve Polik, 1992). Aynı ölçüm aracının k1saltılmış versiyonunun kullanıldığı araştırmada orijinal ölçekte yer alan dört faktörün bütünlüğünü koruyan ölçüm aracında 14 madde yer almış ve tatil motivasyonu ölçeği olarak nitelendirilmiştir. Tatilde mevcut ilişkilerin kurulması ve sürdürülmesi alt boyutu varyansın $\% 22.7 '$ sini, gevşeme alt boyutu \% 17 'sini, entelektüel boyut \% 12.9'unu, son olarak da yeterlilik-ustalık boyutu varyansın\% 9'unu oluşturmaktadır. Alt boyutlar sırasıyla $.81, .76, .60$ ve .64 değerlerini elde etmiştir. Dolayısıyla içsel boş zaman motivasyonu güvenirlik katsayılarının aksine düşük güvenirlik katsayısı elde eden bir ölçüm aracı ortaya koyulmuştur (Ryan ve Glendon, 1998). Tsigilis ve Theodosiou'nun (2003) içsel boş zaman motivasyonu ölçeğinde yer alan test tekrar test yöntemiyle benzer şekilde elde ettiği veriler ile yapılan analizler doğrultusunda üç 
faktörlü bir yapı elde ettiği ve 17. Madde silinerek analiz tekrarlandığında $\% 65 ' 3$ oranında varyansın açıklandığı bir yapı elde edilmiştir. Elde edilen alt boyutlar için iç tutarlılık katsayıları .78 ila .90 arasında değişmektedir. Faktör yüklerinin ise .62 ila .94 arasında değiştiği belirlenmiştir.

Boş zaman motivasyonu ölçeğinin Japonca bir versiyonu, beş faktörlü bir yapı elde etmiş, entelektüel, yetkinlik / ustalık, uyarandan kaçınma, akran etkisi ve dostluk adı altında 5 alt boyuta yer verilmiştir. Toplam varyansın $\% 67$ sinin açıklandığı yapı, .73 ila .99 aralığında iç tutarlılık katsayıları ortaya koymuştur. 5 maddenin silinmesiyle ortaya geçerli ve güvenilir bir yapı çıtığı ifade edilmektedir (Murray ve Nakajima, 1999). Diğer yandan araştırma kapsamında yararlanılan öz belirleme kuramı baz alınarak gerçekleştirilen boş zaman motivasyonu ölçeğinin doğrulayıc faktör analizi ile, her bir alt boyuta dair geçerlik analizleri yapılmış, içsel boş zaan motivasyonu ölçeğinin aksine alt boyutlarını her birinin minimal kabul edilebilir uyum seviyelerini gösterdiği belirlenmiştir. Genel modelin modifikasyon olmadan testi de minimal olarak kabul edilebilir düzeyde olarak değerlendirilmiştir. Diğer yandan bu araştırmada boş zaman motivasyonu ölçeğinde iki maddenin silinmesinin uyum indekslerine yönelik değerleri arttırdığı saptanmıştır. Ölçeğin beş motivasyon formunu ölçmek adına 12-15 yaş arası genç ve ergenlerde kullanılabilir olduğu belirlenmiştir (Baldwin ve Caldwell, 2003). Yine öz belirleme kuramından yararlanılan araştırmada yapısal eşitlik modeli ile öz belirleme teorisinin psikolojik ihtiyaçların motivasyona dair ve psikolojik diğer parametrelerde önemli bir etken olduğu ifade edilmektedir. Model, evrensel motivasyon, bağlamsal ve durumsal motivasyon türlerini arasında oluşturulmuştur. Oluşturulan model motivasyon türlerinin ilişkili olduğunu ve modeli doğruladığını gösterir niteliktedir. Ayrıca psikolojik ihtiyaçların motivasyon ile olan ilişkisinde bireysel farklılıkları göz önünde bulundurmanın önemi göz önüne serilmektedir (Vallerand, 2000).

Boş zaman etkinliklerine katılım motivasyonunu anlamak ve toplumda fiziksel aktiviteye bağllığı artırmak genel refah için oldukça önemlidir. Mevcut düzenlemeler, insanların spor ve egzersiz yapmak için sahip oldukları tüm güdüleri yeterince saptayamamaktadır. Katılım motivasyonu belirlemek amaciyla geliştirilen Fiziksel Aktivite ve Boş Zaman Motivasyonu Ölçeği'nin geçerlik ve güvenirlik analizi yapıldığı bu araştırma kapsamında içsel boş zaman motivasyonu ölçeğine benzer şekilde analiz sonuçları ölçüm aracının geçerli bir yapıya sahip olduğunu göstermektedir $\left(x^{2}=2.22\right.$; NFI = 0.95; CFI = 
0.97; RMSEA = 0.078). İç tutarlılık katsayıları ise toplamda .79 olurken alt boylar arasında .80 ila .99 arasında değişen oldukça yüksek iç tutarlılık değerleri elde edildiği görülmektedir. Araştırma içsel boş zaman motivasyonu ile benzer şekilde geçerli ve güvenilir bir ölçüm aracı ortaya koyulduğunu göstermektedir (Roychowdhury, 2018).

Mutlu (2008) tarafından Türkçe uyarlaması yapılan Boş Zaman Motivasyon Ölçeği alanda sıkça kullanılan bir ölçüm aracıdır. 7 alt boyut ve toplam 28 maddeden oluşan orjinal ölçek 7'li Likert tipidir ve ölçüm aracına yönelik faktör analizi sonucuna göre, kesme değeri .40'ın altında olan 6 maddenin ölçüm aracından çıkartıldığı belirtilmiştir. Faktör yapısını test etmek amacıyla temel bileşenler faktör analizi uygulanmıştır. Analiz sonuçları 5 faktörlü yapıyı desteklemekte ve 212 egzersiz katılımcısı için ölçeğin \% 60'ını açıklamaktadır. Ölçekte yer alan maddelerin faktör yükleri .402, .833 arasında değişmektedir. Faktör analizi sonucunda ortaya çıkan faktörler ise; motivasyonsuzluk, bilmek ve başarmak, uyaran yaşama, özdeşim/ içe atım ve dişsal düzenleme olarak adlandırılmıştır. Cronbach Alpha iç tutarlılık katsayıları 5 alt boyut için .60 ile. 73 arasında değişmektedir. Araştırma bulgularının içsel boş zaman motivasyonu ölçeğiyle benzer şekilde geçerli ve güvenilir bir yapıda olduğu belirlenmiştir.

Sonuç olarak katılımcıların içsel boş zaman motivasyonunun belirlenmesine yönelik geliştirilen ölçüm aracı, boş zamanlara yönelik içsel motivasyon eğilimlerini ölçmede geçerli ve güvenilir bir araç olarak ortaya koyulmuştur. Geliştirilen ölçüm aracı boş zaman aktivitelerine katılımın altında yatan psikolojik ve sosyolojik faktörlerin aydınlatılmasında etkili ve verimli biçimde kullanılabilir. Bireylerin boş zaman değerlendirme davranışlarının içsel nedenlerinin aydınlatılması, aynı zamanda rekreasyon hizmetleri sağlayıcılarının mevcut programların bireylerin ihtiyaç ve eğilimleri doğrultusuna geliştirmesi adına önemli bir unsurdur. 


\title{
EXTENDED ABSTRACT
}

\section{Validity and Reliability Analysis of Intrinsic Leisure Motivation Scale}

\author{
Ali Selman Özdemir - Tebessüm Ayyıldız Durhan - Suat Karaküçük \\ International Kıbrıs University, Gazi University
}

When the individual is motivated internally, he acts to have fun or to engage in activity, rather than external factors, pressures or rewards. Intrinsic motivation is clearly visible in babies who are constantly trying to grasp, throw, bite, crush, or make new objects they encounter. Adults are generally selfmotivated when solving puzzles, painting, gardening, reading books or watching movies. In short, an individual's anxiety or fear of being left off the lesson, which allows him / her to work compulsively to a lesson that he / she does not like, is external motivation, and that he / she takes extra work or takes responsibility in the name of the class without any coercion or anxiety for a lesson he / she likes and is interested in.

Intrinsic motivation theory, in the international literature; Therapeutic recreation has been applied on various leisure areas such as children's games, physical health, flow, assessment of leisure services, abandonment of leisure activity, recreational shopping and recreational tourism (Levy, 1971; Csikszentmihalyi, 1975b; Weissinger and Iso -Ahola, 1984; Iso-Ahola, 1982; Mannell, Zuzanek and Larson, 1988; Backman and Crompton, 1990; Lesser and Forsythe, 1989; Iso-Ahola, 1983). When the literature is examined, it is seen that there is a limited number of scale development and adaptation studies in our country on leisure motivations (Gürbüz, 2006; Güngörmış, 2012; Özdemir et al., 2016).

The purpose of this study; Based on the work of Deci, Ryan (1985a), Kobasa (1979) and friends, which are believed to make an important contribution to the illumination of individuals' leisure preferences and behaviors, to redesign their leisure services and programs in accordance with the needs, and to develop the development of educational behaviors in the psychology of leisure time. It is to test the validity and reliability of the scale developed by Bandalos (1995) and its original name is "Instrinsic Motivation Scale" in Turkish. 
Based on the research of Deci, Ryan (1985a), Kobasa (1979) and friends, Weissinger and Bandalos (1995); In the research, which was developed to measure the individual differences in intrinsic motivation tendency in leisure behaviors and aimed to test its validity and reliability by making a Turkish adaptation of the scale whose original name was "Instrinsic Motivation Scale (ILM) ", the original version of the scale was 24 items and It consists of four sub-dimensions. The current research is based on the analysis made in the light of the data collected from 748 students with the test-retest method. Data were subjected to KMO-Barlett test with 353 participants and exploratory factor analysis was used after determining that the sample size was suitable for analysis $(.92 ; 3366,957, \mathrm{p}<0.001)$. An attempt was made to establish a valid structure with exploratory factor analysis, and the final scale form consisting of 5 sub-dimensions and 23 items was reached. As a result of the exploratory factor analysis, the cutoff value was taken as .40 and it was found that the variance value explained was $57.53 \%$ in total, and it was found to be collected under 5 sub-dimensions in the analysis of rotated components. The 7th item, which was determined to load each other from the scale items, was removed from the test. In addition, 5. Sub-dimension items are reversed. After the second data collection on 395 participants using the test-retest method, the structure was tested by confirmatory factor analysis. Confirmatory factor analysis appears to provide evidence of construct validity (RMSEA .070, NFI 0.96, CFI 0.96, NNFI 0.96, $\mathrm{x}^{2}$ / df 2.94).

Understanding the motivation to participate in leisure activities and increasing commitment to physical activity in the community is crucial for general well-being. The current regulations do not adequately identify all the motivations people have for exercising and exercising. As a result, the measurement tool developed for determining the inner leisure motivation of the participants was presented as a valid and reliable tool for measuring the inner motivational tendencies for leisure. The developed measurement tool can be used effectively and efficiently in elucidating the psychological and sociological factors underlying participation in leisure activities. Clarifying the intrinsic causes of individuals' leisure-time behaviors is also an important element for recreation services providers to develop their existing programs in line with the needs and trends of individuals. 


\section{Kaynakça / References}

Backman, S.J., ve Crompton,J.L. (1990). Differentiating between active and passive discontinuers of two leisure activities. Journal of Leisure Research, 22, 197-212.

Baldwin ,C.K. ve Caldwell, L.L.(2003) Development of the free time motivation scale for adolescents. Journal of Leisure Research, 35(2), 129-151, DOI: 10.1080/00222216.2003.11949987.

Beard, J. G. ve Ragheb, M. G. (1983). Measuring leisure motivation. Journal of Leisure Research, 15, 219-228.

Bradley, W. ve Mannell, R. (August, 1982). The effects of extrinsic rewards and reward procedures on intrinsic motivation and psychological experience offlow during play. Paper presented at the American Psychological Association Annual Convention, Washington, DC.

Chen, M. ve Pang, X. (2012). Leisure motivation: An integrative review. Social Behavior \& Personality: An International Journal, 40(7), 1075-1081.

Chen, M. ve Pang, X. (2012). Leisure motivation: An integrative review. Social Behavior And Personality, 40(7), 1075-1082. http://dx.doi.org/10.2224/sbp.2012.40.7.1075.

Clancy, R.B., Herring, M.P., MacIntyre, T.E. ve Campbell, M.J. (2016). A review of competitive sport motivation research. Psychology of Sport and Exercise, 27, 232-242.

Coleman, R., ve Barrie, G., (2000). Yöneticinin kılavuzu: Iyi bir yönetici olmak için 525 kural. (Çev. Harmanc1, M.), İstanbul: Remzi Kitabevi.

Csikszentmihalyi, M. (1975). Play and intrinsic rewards. Journal of Humanistic Psychology, 75(3), 41-63.

Csikszentmihalyi, M. (1990). Literacy and intrinsic motivation. Daedalus, 119(2), $115-14$.

Deci, E. L. (1975). Intrinsic motivation. New York: Plenum Press.

Deci, E. L., ve Ryan, R. M. (1985). Intrinsic motivation and self-determination in human behavior. New York: Plenum Press.

Deci, E. L., ve Ryan, R. M. (1991). A motivational approach to self: Integration in personality. R. Dienstbier (Ed.), proceedings of Nebraska Symposium on Motivation: Perspectives on motivation içinde(Cilt.38, s.237288). Lincoln, NE: University of Nebraska Press.

Deci, E. L., Vallerand, R. J., Pelletier, L. G., ve Ryan, R. M. (1991). Motivation and education: The self-determination perspective. Educational Psychologist, 26(3-4), 325-346. 
Deci, E.L., ve Ryan, R.M. (1985). Intrinsic motivation and self-determination in human behavior. New York: Plenum.

Dillard, J. E., Bates,D.L. (2011) Leisure motivation revisited: why people recreate. Managing Leisure, 16(4), 253-268, DOI: 10.1080/13606719.2011.613624.

Gungormus, H.A., (2012). The Study of Validity and Reliability of Turkish Version of Leisure Motivation Scale. Energy Education Science and Technology Part B: Social and Educational Studies, 4(3), 1209-1216.

Gürbüz B., Aşçı F.H. ve Çelebi M. (2006). The reliability and validity of the Turkish version of the "recreational exercise motivation measure. 9th International Sport Sciences Congress, 3-5 November, Muğla, Turkey. 1044.

Iso-Ahola, S. (1999). Motivational foundations of leisure. E. L.Jackson ve T. L. Burton (Eds.), Leisure Studies: Prospects for the Twenty-First Century içinde (s. 35-51). State College, PA: Venture Publishing.

Iso-Ahola, S.E. (1982). Intrinsic motivation: An overlooked basis for evaluation. Parks and Recreation, 17,32-33,58.

Iso-Ahola, S.E. (1983). Toward a social psychology of recreational travel. Leisure Studies, 2, 35-4.

Kobasa, S. (1979). Stressful life events, personality and health: An inquiry into hardiness. Journal of Personality and Social Psychology, 37, 1-11.

Konstantinos, A., Tsorbatzoudis, C. ve Grouios, G. (2002). Perceived constraints on recreational sport participation: Investigating their relationship with intrinsic motivation, extrinsic motivation and amotivation. Journal of Leisure Research, 34(3) 233-252.

Lesser, J. A., ve Forsythe, S. M. (1989). Antecedents and consequences of the intrinsic motivation to shop. Psychological Reports, 64(3), 1183-1191.

Levy, J. (1971). An intrinsic-extrinsic framework for therapeutic recreation. Therapeutic Recreation Journal, 1, 32-38.

Lounsbury, J., Polik, J. (1992). Leisure needs and vacation satisfaction. Leisure Sciences, 14, 105-119. http://doi.org/gth.

Manfredo, M.J., Driver, B.L., Tarrant, M.A. (1996). Measuring leisure motivation: A meta-analysis of the recreation experience preference scales. Journal of Leisure Research; 28(3), 188-213.; ProQuest Environmental Science Collection pg.

Mannell, R.C., Zuzanek, J., ve Larson, R. (1988). Leisure states and "flow" experiences: Testing perceived freedom and intrinsic motivation hypothesis. Journal of Leisure Research, 20, 289- 304. 
Murray,C., Nakajima, I. (1999) The leisure motivation of Japanese managers: a research note on scale development. Leisure Studies, 18(1), 57-65, DOI:10.1080/026143699375050.

Mutlu, İ. (2008). Egzersiz yapan kişilerin boş zamanlarına yönelik tutumlar üzerine bir araştırma:Kayseri İli örneği. Yayımlanmamış Yüksek Lisans Tezi, Niğde Üniversitesi, Sosyal Bilimler Enstitüsü, Niğde.

Özdemir, A. S., Büyüköztürk, Ş., ve Karaküçük, S. (2016). Explaining destination choices based upon recreational opportunities through intrinsic and extrinsic travel motivations. Journal of Human Sciences, 13(2), 3002-3021.

Roychowdhury, D. (2018). A comprehensive measure of participation motivation: Examining and validating the Physical Activity and Leisure Motivation Scale (PALMS). Journal of Human Sport and Exercise, 13(1), 231-247. doi:https://doi.org/10.14198/jhse.2018.131.20

Ryan, C., ve Glendon, I. (1998). Application of leisure motivation scale to tourism. Annals of Tourism Research, 25, 169-184. http://doi.org/gtn.

Ryan, R. M., and Deci, E. L. (2000a). Intrinsic and extrinsic motivations: classic definitions and new directions. Contemp. Educ. Psychol. 25, 54-67.

Ryan, R. M. ve Deci, E. L. (2000b). Self-determination theory and the facilitation of intrinsic motivation, social development, and well-being. American Psychologist. 55(1) 68-78.

Vallerand, R.J. (2000). Deci and Ryan's self-determination theory: A view from the hierarchical model of intrinsic and extrinsic motivation. Psychological Inquiry, 11(4), 312-318.

Weissinger, E., ve Bandalos, D. (1995). Development, reliability and validity of a scale to measure intrinsic motivation in leisure. Journal of Leisure Research, 27, 379-400.

Weissinger, E., ve Bandalos, D. L. (1995). Development, reliability and validity of a scale to measure intrinsic motivation in leisure. Journal of Leisure Research, 27, 379-400.

White, R. W. (1959). Motivation reconsidered. Psychological Review, 66, 297-333. 
Ek 1. İçsel Boş Zaman Motivasyonu Ölçeği Madde Dağılımı

\begin{tabular}{ll}
\hline Mücadele/yeterlik & $4,5,8,9,10,14,15,16$, \\
\hline Öz belirleme & $17,19,21,22,23,24$ \\
\hline Bağlllık & $1,2,3$ \\
\hline Özdeşim & $11,12,20$ \\
\hline Motivasyonsuzluk & $6,13,18$ \\
\hline
\end{tabular}

*Ters kodlanan maddeler

\section{Kaynakça Bilgisi / Citation Information}

Özdemir, A. S., Ayyıldız Durhan, T. ve Karaküçük, S. (2020). İçsel boş zaman motivasyon ölçeği geçerlilik ve güvenirlik çalışması. OPUSUluslararası Toplum Araştırmaları Dergisi, 15(24), 2838-2855. DOI: 10.26466-/opus.705201 